\title{
X-Ray diffraction and Raman spectroscopy for a better understanding of $\mathrm{ZnO}: \mathrm{Al}$ growth process
}

\author{
C. Charpentier ${ }^{1,2, a}$, P. Prod'homme ${ }^{1}$, I. Maurin ${ }^{3}$, M. Chaigneau ${ }^{2}$, and P. Roca i Cabarrocas ${ }^{2}$ \\ 1 TOTAL SA - Gas \& Power R\&D Division Tour Lafayette, 2 place des Vosges La Défense 6, 92400 Courbevoie, France \\ 2 LPICM-CNRS - Laboratoire de Physique des Interfaces et Couches Minces, École Polytechnique, 91128 Palaiseau, France \\ 3 LPMC-CNRS - Laboratoire de Physique de la Matière Condensée, École Polytechnique, 91128 Palaiseau, France
}

Received: 20 July 2011 / Accepted: 3 October 2011

Published online: 17 January 2012

\begin{abstract}
ZnO}: \mathrm{Al}$ thin films were prepared on glass substrates by radio frequency $\mathrm{RF}$ magnetron sputtering from a ceramic $\mathrm{ZnO}$ target mixed with $\mathrm{Al}_{2} \mathrm{O}_{3}$ (1 wt\%) in pure argon atmosphere with a power of $250 \mathrm{~W}$. Two series of samples were deposited, the first one as a function of the substrate temperature (between 20 and $325^{\circ} \mathrm{C}$ ) at $0.12 \mathrm{~Pa}$, the second one as a function of the working pressure (between 0.01 and $2.2 \mathrm{~Pa}$ ) at room temperature. The influence of these deposition parameters was studied by a detailed microstructural analysis using X-Ray diffraction and Raman spectroscopy. Their electrical properties were characterized by Hall effect measurements. As the substrate temperature is increased, crystallite size increases while the strain and the electrical resistivity decrease. An improvement of the crystallinity is deduced from Raman spectra and X-Ray diffraction patterns. From the pressure series, an electrical optimum is observed at $0.12 \mathrm{~Pa}$. Above $0.12 \mathrm{~Pa}$, there is a degradation of the crystallinity, attributed to the low mobility of the adatoms and below $0.12 \mathrm{~Pa}$, high-energy sputtered particles damage the growing films. The trends given by Thornton structure zone model are also consistent with X-Ray diffraction results.
\end{abstract}

\section{Introduction}

In $\mu \mathrm{c}-\mathrm{Si}: \mathrm{H}$ solar cells, doped and intrinsic layers are packed between a transparent conductive oxide (TCO) front contact and a highly reflective back contact. In the PIN configuration light enters through the glass and TCO layer and is trapped into the intrinsic layer by the light scattering properties of the TCO layer and by reflection on back contacts. TCOs are a key point for improvement of $\mu \mathrm{c}-\mathrm{Si}: \mathrm{H}$ solar cells [1-4]. The TCO front contact must meet a number of requirements. This layer must be highly transparent in the active wavelength range of the absorber layer, between 400 and $1100 \mathrm{~nm}$ for $\mu \mathrm{c}-\mathrm{Si}: \mathrm{H}$, and also highly conductive to avoid ohmic losses. In the PIN structure, the front contact additionally has to possess a rough surface to provide efficient light scattering and must feature favourable physical and chemical properties for an efficient growth of $\mu \mathrm{c}-\mathrm{Si}: \mathrm{H}$. For example, TCO has to be inert to hydrogen-rich plasmas and a high work function is required in order to provide an ohmic TCO/p-contact for cell performance.

A promising TCO material is aluminium doped zinc oxide because of its low cost, non-toxicity, high stability against hydrogen plasma and high surface texturability $[5,6]$. Highly conductive and transparent in the visible range $\mathrm{Al}$-doped $\mathrm{ZnO}$ thin films have been deposited by $\mathrm{RF}$ magnetron sputtering. This deposition technique enables

${ }^{a}$ e-mail: coralie.charpentier@polytechnique.edu a high deposition rate, a low process temperature and a dense layer formation [7-9]. An optimized light trapping is achieved by a wet-chemical etching step after vacuum deposition.

Many studies have addressed the correlation between deposition parameters and quality of the films [8-16]. A deeper understanding of the relationship between different sputter process conditions, growth process and microstructure is still required to further optimize electrical and optical properties of the films. In this work, we study the influence of the deposition temperature and working pressure on the microstructural and electrical properties of $\mathrm{ZnO}: \mathrm{Al}$ thin films prepared by $\mathrm{RF}$ magnetron sputtering on glass substrates. A wide variety of characterization techniques is used, including atomic force microscopy (AFM) and Hall effect measurements. Moreover, a detailed analysis of X-Ray diffraction data using Williamson-Hall plots [17-19] complemented by Raman spectroscopy [19-23] was performed to obtain additional information on microstructure, crystallinity and defects in the films.

\section{Experiments}

\section{$2.1 \mathrm{ZnO}$ :Al film deposition}

ZnO:Al films were deposited on glass substrates by $\mathrm{RF}$ magnetron sputtering using a $\mathrm{ZnO} / 1 \mathrm{wt} \% \mathrm{Al}_{2} \mathrm{O}_{3}$ as 
a ceramic target of $152 \mathrm{~mm}$ in diameter, and a RF power of $250 \mathrm{~W}$. The base pressure was $4 \times 10^{-5} \mathrm{~Pa}$ and the working pressure was controlled by the flow rate of argon regulated by a mass flow controller.

For the first set of samples grown at different substrate temperatures, depositions were carried out between room temperature around $20^{\circ} \mathrm{C}\left( \pm 5^{\circ} \mathrm{C}\right.$ for temperature without set point) and $325{ }^{\circ} \mathrm{C}\left( \pm 1{ }^{\circ} \mathrm{C}\right.$ for temperature regulated by set point value) at a working pressure of $0.12 \mathrm{~Pa}$ in pure argon atmosphere. For the second set of samples prepared at room temperature, depositions were carried out in the working pressure range of $0.01 \mathrm{~Pa}$ to $2.2 \mathrm{~Pa}$. A non-intentional increase of the substrate temperature during the sputtering can be observed up to a maximum of $10^{\circ} \mathrm{C}$ independently of the working pressure. The X-Ray diffraction (XRD) patterns were recorded with a PANalytical X'Pert powder diffractometer equipped with a $\mathrm{Cu} \mathrm{K} \alpha$ radiation $(\lambda=1.5418 \AA)$. The Raman experimental setup consists of a high-resolution $\left(0.1 \mathrm{~cm}^{-1}\right)$ Raman spectrometer (Labram HR800 from HORIBA Jobin Yvon) in a confocal microscope backscattering configuration. The accommodate objective used in this study was a $100 \times(\mathrm{NA}=$ 0.9) objective from Olympus. A tunable Ar laser (514 nm wavelength) was employed in this confocal configuration. For all the Raman Stokes analysis, the collection time was $10 \mathrm{~s}$ with 6 consecutive spectrum accumulations. Surface morphology was characterized by AFM in tapping mode (Agilent Technologies 5500). A HMS5000 from Microworld was used to obtain the Hall mobility, carrier concentration and resistivity of the films by Hall effect.

All studies were carried out on films of approximately the same thickness $(1000 \pm 100 \mathrm{~nm})$ estimated by ellipsometric analysis. This thickness corresponds to a good compromise for the use of this layer as front contact in $\mu \mathrm{c}-\mathrm{Si}: \mathrm{H}$ solar cells, between the highest transmission in the visible range and the lowest resistivity.

\subsection{Microstructural analyses}

\subsubsection{X-Ray diffraction}

All the films exhibit a strong $c$-axis preferred orientation revealed by the high intensity of the (002) reflection of ZnO:Al Würtzite structure (Fig. 1) [12-17, 19]. These strongly oriented grains will be referred to crystallites in the following, with a given vertical coherence length called from now crystallite size. Crystallite size and strain can be obtained from the distribution of the scattered intensity in reciprocal space. The crystallite size is correlated with a reciprocal lattice point broadening in the $q_{Z}$ direction perpendicular to the substrate plane. In the radialscan direction $(\theta-2 \theta$ scans $)$ of the symmetric reflections of (002), (004), and (006), a reduced correlation length normal to the substrate plane and a heterogeneous strain along the $c$-axis are responsible for the broadening of the Bragg reflections. Broadening in reciprocal space due to finite size effects is independent of the scattering vector $q_{Z}$, but the broadening associated with strain is proportional to the scattering order. A graphical separation of these

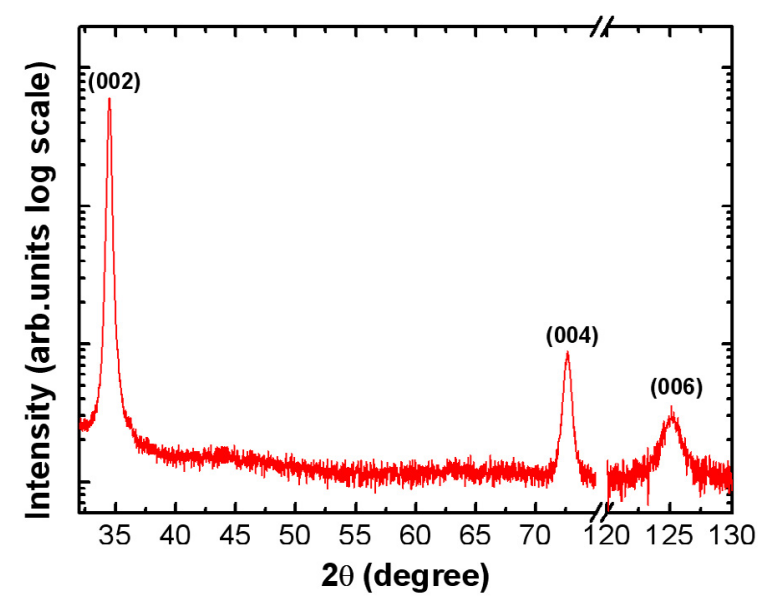

Fig. 1. (Color online) XRD profile of $\mathrm{ZnO}$ :Al film deposited on glass substrate at room temperature, RF power of $250 \mathrm{~W}$ and Ar pressure of $0.12 \mathrm{~Pa}$.

two effects owing to their different dependence on $q_{Z}$ is possible by recording high-order reflections and using Williamson-Hall plots $[17,18]$. The (002), (004) and (006) peaks were fitted to a linear combination of Gauss and Cauchy functions (Pseudo-Voigt function) to determine the Full Width at Half Maximum FWHM called $\beta_{\text {exp }}$ in the following.

FWHM values have to be corrected from instrumental broadening following equation (1) for a Gauss profile, or equation (2) for a Cauchy profile:

$$
\begin{gathered}
\beta^{2}=\beta_{\text {exp }}^{2}-\beta_{i n s t r}^{2} \\
\beta=\beta_{\text {exp }}-\beta_{\text {instr }} .
\end{gathered}
$$

For Williamson-Hall plots, $(\beta \cos \theta / \lambda)^{2}$ is plotted against $(2 \sin \theta / \lambda)^{2}$ for each reflection for Gauss profiles or alternatively, $\beta \cos \theta / \lambda$ is plotted against $2 \sin \theta / \lambda$ for Cauchy profiles. $\lambda$ and $\theta$ are the wavelength and the incident angle of the X-rays, respectively. The crystallite size $D$ and strain $\varepsilon$ can be respectively estimated from the intercept and slope of the linear Williamson-Hall plots following equation (3) for a Gauss profile or equation (4) for a Cauchy one.

$$
\begin{gathered}
(\beta \cos \theta / \lambda)^{2}=(1 / D)^{2}+(\varepsilon 2 \sin \theta / \lambda)^{2} \\
\beta \cos \theta / \lambda=1 / D+\varepsilon 2 \sin \theta / \lambda .
\end{gathered}
$$

In the present case, the Cauchy and Gauss contributions in the Pseudo-Voigt function are obtained by the fit of the FWHM for the (002), (004) and (006) peaks and are equal, so none of these equations are strictly valid for Williamson-Hall. Nonetheless, we observed that the strain extracted either from equation (3) or from equation (4) are similar $( \pm 3 \%)$. The values presented in the following correspond to the average. In contrast, a Cauchy approximation systematically underestimates the width of the reflections after correction of the instrumental resolution and that of the transverse coherence length. In the following, values obtained from Gauss analyses were used to qualitatively estimate the crystallite size. 


\subsubsection{Raman spectroscopy}

Raman spectroscopy gives information on vibrational properties of $\mathrm{ZnO}$. In hexagonal structures with $\mathrm{C}_{6 \mathrm{v}}^{4}$ symmetry like $\mathrm{ZnO}$, six sets of phonon normal modes at the $\Gamma$ point (centre of the Brillouin zone) are optically active modes $[19,20,23]$. The phonons for Würtzite $\mathrm{ZnO}$ belong to the following irreducible representation:

$$
\Gamma=A_{1}+E_{1}+2 B_{1}+2 E_{2} .
$$

Where both $A_{1}$ and $E_{1}$ modes are polar, and split into transverse optical modes $\left(A_{1}-\mathrm{TO}\right.$ and $\left.E_{1}-\mathrm{TO}\right)$, resulting from beating in the basal plane, and longitudinal optical modes $\left(A_{1}\right.$-LO and $\left.E_{1}-\mathrm{LO}\right)$, resulting from beating along the $c$-axis, with different frequencies due to the macroscopic electric fields associated with LO phonons. For lattice vibrations with $A_{1}$ and $E_{1}$ symmetry, the atoms move parallel and perpendicular to the $c$-axis, respectively. The $A_{1}$ and $E_{1}$ branches are both Raman and infrared active, the two nonpolar $E_{2}$ branches are Raman active only, and the $B_{1}$ branches are inactive [23].

In addition to the selection rules mentioned above for Raman-active phonon modes, the modes to be detected by Raman scattering spectroscopy also depend on the scattering geometry. The selection rules and the backscattering geometry of our Raman system imply that the two $E_{2}$ modes and the $A_{1}$-LO modes are expected while all other modes are forbidden. The $E_{2}$ modes at low and high frequency and the $A_{1}$-LO mode are respectively at $101 \mathrm{~cm}^{-1}$, $437 \mathrm{~cm}^{-1}$ and $574 \mathrm{~cm}^{-1}$. The $E_{2}$ (low-frequency) mode is associated with the vibration of the heavy $\mathrm{Zn}$ sublattice, while the $E_{2}$ (high-frequency) mode involves only oxygen atoms [23].

\section{Results and discussion}

\subsection{Influence of the substrate temperature}

\subsubsection{Microstructural properties}

The Raman spectra of this series of $\mathrm{ZnO}$ :Al thin films are dominated by the $A_{1}$ - $\mathrm{LO}$ vibrations around $578 \mathrm{~cm}^{-1}$ (Fig. 2). This band, which is highly asymmetric, arises from two contributions, a low wavenumber contribution and a high wavenumber one.

The Raman spectra provide qualitative information about the crystallinity of the films. Indeed, the relative area of the disordered (low wavenumber contribution) and crystalline (high wavenumber contribution) peaks enable to compare the degree of crystallinity corresponding to different spectra. For the results listed in Table 1, peaks were fitted to pure Gauss profiles, with a linear baseline from 525 to $625 \mathrm{~cm}^{-1}$ which reproduces quite well the glass substrate contribution. The two peaks used for the deconvolution are attributed to different phases present in the sample: the narrow peak centred around $578 \mathrm{~cm}^{-1}$ is attributed to $\mathrm{ZnO}: \mathrm{Al}$ crystallites while the broad peak around $560 \mathrm{~cm}^{-1}$ is characteristic of a disordered phase

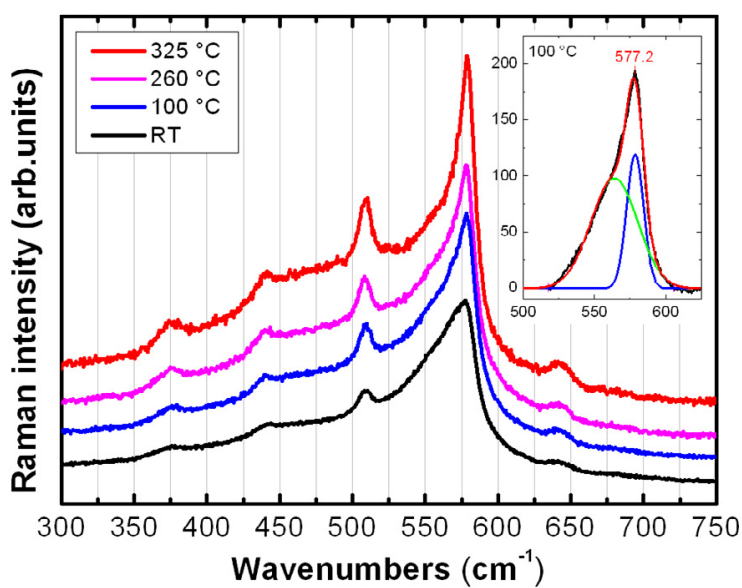

Fig. 2. (Color online) Raman spectra of $\mathrm{ZnO}$ :Al films deposited at various temperatures. The asymmetric $A_{1}$-LO vibration is fitted to two Gaussian contributions (example given in the inset).

Table 1. Relative amount of the crystalline and disordered contributions derived from the deconvolution of the $A_{1}-\mathrm{LO}$ Raman mode as a function of the substrate temperature.

\begin{tabular}{lcccc}
\hline $\begin{array}{l}\text { Ts } \\
\left({ }^{\circ} \mathrm{C}\right)\end{array}$ & $\mathrm{RT}$ & 100 & 260 & 325 \\
\hline $\begin{array}{l}\text { Peak position } \\
\left(\mathrm{cm}^{-1}\right)\end{array}$ & 576.1 & 577.2 & 577.7 & 578.2 \\
$\begin{array}{l}\text { \% Area } \\
\text { Crystalline/ }\end{array}$ & 24 & 30 & 30 & 36 \\
Disordered & & & & \\
\hline
\end{tabular}

(Fig. 2). For the present time, values of the Table 1 have to be considered as semi-quantitative as the fitting procedure of the $A_{1}$-LO peak has not been optimized.

With increasing temperature, the high wavenumber contribution increases compared to the low wavenumber contribution (Tab. 1). This trend suggests an improvement of the crystallinity and a reduction in defects of the $\mathrm{ZnO}$ :Al films.

Some additional weak peaks are observed at $380 \mathrm{~cm}^{-1}$ and $501 \mathrm{~cm}^{-1}$. The first one can be assigned to the $A_{1^{-}}$ TO mode. This mode is not expected to appear in Raman backscattering geometry for single crystalline $\mathrm{ZnO}$ and could arise from the polycrystalline character of the films. The second peak at $501 \mathrm{~cm}^{-1}$ is possibly related to the doping of the zinc oxide layer and to the charge carrier concentration $[20,21]$.

The improvement of crystallinity observed in Raman spectra with increasing temperature is also observed by $\mathrm{X}$-Ray diffraction, from the increase of the intensity of the (002) peak. It is correlated with an increase of the crystallite size deduced from X-Ray diffraction analyses (Fig. 3), which is attributed to an increase in surface diffusion of the adsorbed species. The crystallite size varies from $70 \mathrm{~nm}$ for a sample deposited at room temperature to $100 \mathrm{~nm}$ at a substrate temperature of $325^{\circ} \mathrm{C}$. In parallel, the strain decreases with increasing substrate temperature, because of thermal annealing. The improvement of the crystallinity 


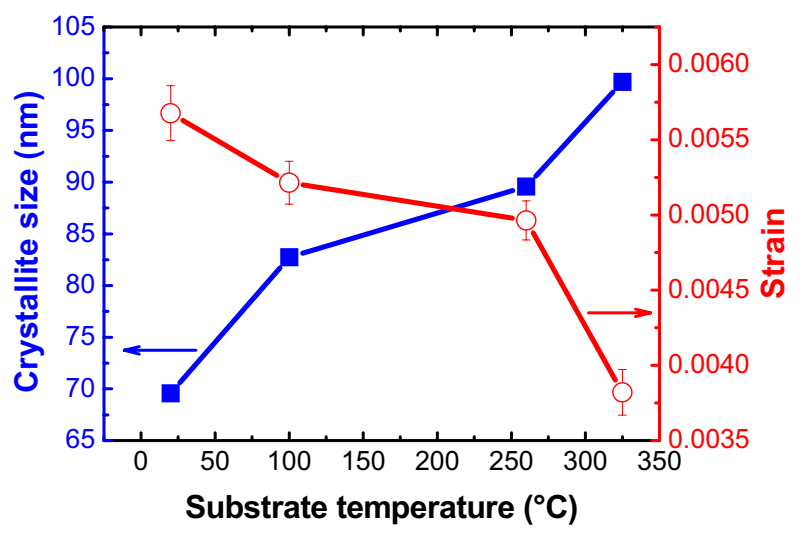

Fig. 3. (Color online) Crystallite size (ם) and strain (\$) estimated from Williamson-Hall plots for samples deposited at various substrate temperatures.

leads to a reduction in defect density inside the films which involves a network relaxation $[15,17,19]$. The strain is also an indication of the crystalline quality of the layer. A decrease in strain indicates an improvement of the crystallinity of the film.

\subsubsection{Morphological studies}

The growth of thin films can be described by a process involving various steps. The first one is nucleation, when the dispersed individual crystalline nuclei are randomly oriented on the amorphous substrate. The second step consists of the island growth. Coalescence of islands leads to the last step of the process, the column growth [24,25]. During the deposition of $\mathrm{ZnO}: \mathrm{Al}$ on glass substrate, the initial nuclei may contain all possible orientations, and crystals growing from these nuclei are randomly oriented. The complete coalescence of the islands induces the formation of polycrystalline areas and channels which leads to the development of polycrystalline films by columnar growth of grains perpendicularly to the substrate plane. The columnar texture of the film is ascribed to the competitive growth of crystals, due to the different growth rates in various crystallographic directions. In $\mathrm{ZnO}$ case, the growth competition favours the (002) orientation over the others (Fig. 1).

Film microstructure is consistent with the trend given by Thornton's structure zone model where $T$ and $T m$ are respectively the substrate temperature and $\mathrm{ZnO}$ melting point (Fig. 4) [26,27]. With the increase of the substrate temperature, a transition from tapered crystallites separated by voids zone (Zone I) to a densely packed fibrous grains zone (Zone T) is observed. The increase of the crystallite size along the growth direction with substrate temperature (Fig. 3) is accompanied with an increase of the lateral dimension of the columns observed on the top of the film in AFM images (Fig. 5). The two structure zones have not the same X-Ray diffraction profiles. All the films have a $c$-axis preferred orientation but additional (101), (102), (103) and (112) peaks appear with increasing substrate temperature (Fig. 6) [14].
Table 2. Relative amount of the crystalline and disordered contributions derived from the deconvolution of the $A_{1}-\mathrm{LO}$ Raman mode as a function of the substrate temperature.

\begin{tabular}{lccccc}
\hline $\begin{array}{l}\text { Working } \\
\text { pressure (Pa) }\end{array}$ & 0.01 & 0.12 & 0.32 & 1.3 & 2.2 \\
\hline $\begin{array}{l}\text { Peak position } \\
\left(\mathrm{cm}^{-1}\right)\end{array}$ & 576.7 & 576.1 & 568.7 & 553.8 & 552.2 \\
$\begin{array}{l}\% \text { Area } \\
\text { Crystalline/ }\end{array}$ & 28 & 24 & 12 & 0 & 0 \\
Disordered & & & & & \\
\hline
\end{tabular}

At low substrate temperature, in zone I, the film consists of tapered crystallites separated by voids (Fig. 4), the surface of the glass substrate is covered by a high density of small nuclei. Crystalline grains grow out of these primary nuclei until the top of the film and the (002) oriented grains rapidly dominate over the other orientations. The nucleation density determines the lateral size of the fibres which are growing uninterruptedly side by side. No minor orientations are observed in X-Ray diffraction diagrams (Fig. 6).

At high substrate temperature, in zone T, the film consists of densely packed fibrous grains (Fig. 4), atoms on the surface of the glass substrate are highly energetic. The surface is covered of a low density of large islands, leading to a competitive growth of differently oriented neighbouring islands and thus $\mathrm{V}$-shaped columns. The lateral growth of the grains is faster than the vertical growth. Minor orientations like (101), (102), (103) and (112) are observed, coming from the region between glass and $\mathrm{ZnO}: \mathrm{Al}$, at the interface (Fig. 6). This hypothesis is supported by the $\mathrm{X}$-Ray diffraction profiles of $\mathrm{ZnO}$ :Al with different thicknesses. For the same deposition conditions, the area of minor orientations increases comparing to the area of (002) orientation when thickness decreases.

\subsubsection{Electrical properties}

With the increase of the substrate temperature, an increase of the carrier concentration and of the Hall mobility, resulting in a decrease of the resistivity, are observed (Fig. 7). This improvement of the electrical properties is related to an increase of the layer density and an increase in crystallite size along the growth direction for films deposited at high substrate temperature which results in a decrease in grain boundaries that act as scattering centres for charge carriers.

\subsection{Influence of the working pressure}

\subsubsection{Microstructural properties}

The working pressure has a strong influence on film microstructure and on the Raman spectra (Fig. 8). The position of the $A_{1}$-LO band gradually varies from $552 \mathrm{~cm}^{-1}$ at $2.2 \mathrm{~Pa}$ to $577 \mathrm{~cm}^{-1}$ at $0.01 \mathrm{~Pa}$ (Tab. 2). The apparent shift of LO modes towards lower wavenumbers is due to the increase of the low wavenumber contribution compared to 


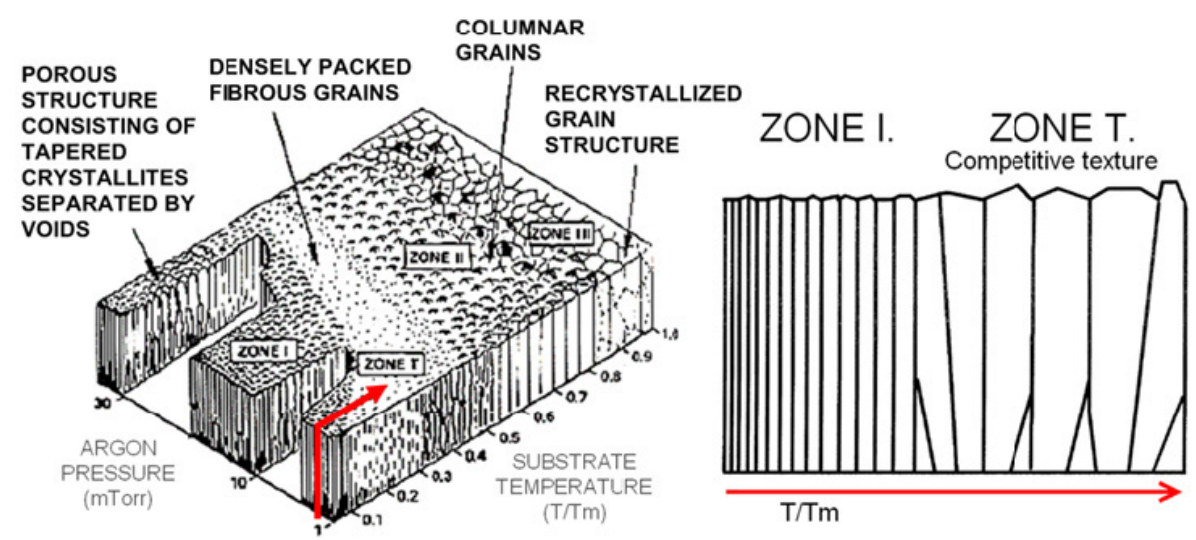

Fig. 4. (Color online) Thornton structure zone model correlating the argon pressure and the substrate temperature to the morphological properties of the films. When increasing the substrate temperature from room temperature to $325^{\circ} \mathrm{C}$, at $0.12 \mathrm{~Pa}$, the structure of the film transits from zone I to zone T [24,26, 27].

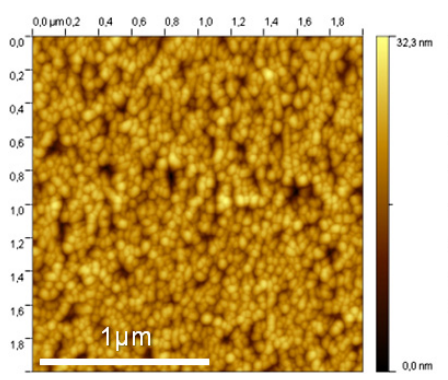

(a)

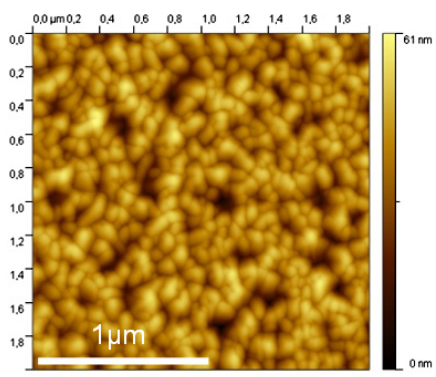

(b)

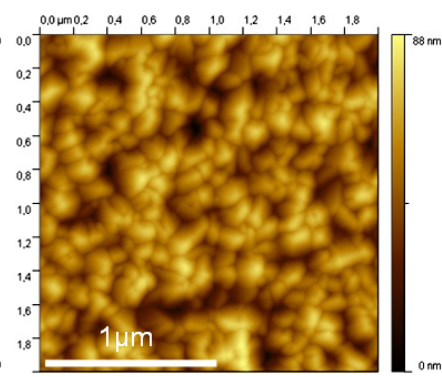

(c)

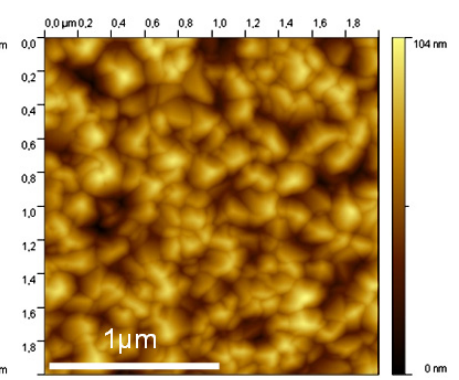

(d)

Fig. 5. (Color online) AFM images of the $\mathrm{ZnO}$ : Al films as function of substrate temperature: (a) room temperature, (b) $100{ }^{\circ} \mathrm{C}$, (c) $260{ }^{\circ} \mathrm{C}$ and (d) $325^{\circ} \mathrm{C}$.

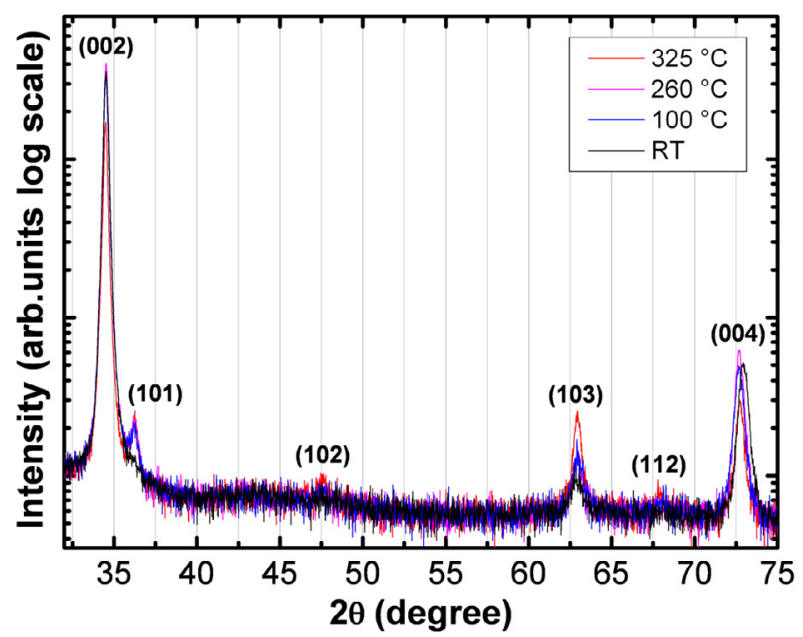

Fig. 6. (Color online) XRD profiles of $\mathrm{ZnO}: \mathrm{Al}$ films for various substrate temperatures.

the high wavenumber contribution with increasing working pressure. This effect is attributed to an increase in defects. This increase correlates well with the significant increase in strain and the decrease in crystallinity estimated from the decrease of the intensity of (002) reflection at high deposition gas pressure (Fig. 9).

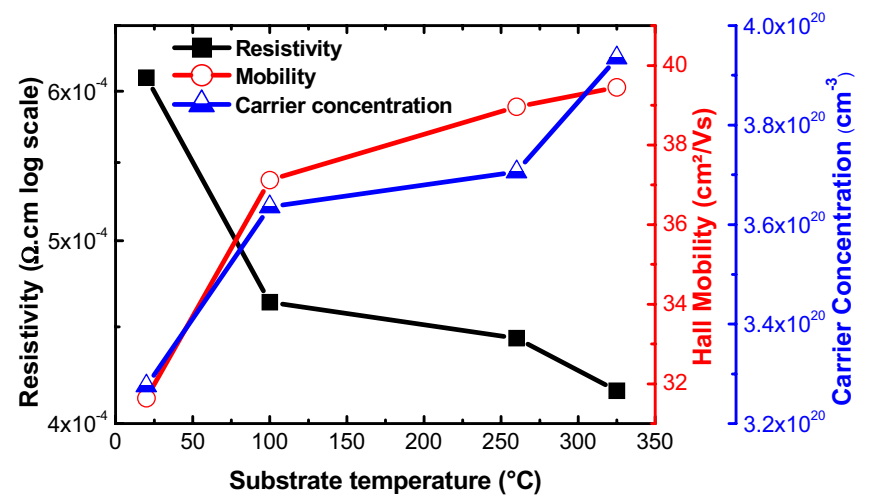

Fig. 7. (Color online) Resistivity (घ), Hall mobility (○) and carrier concentration $(\boldsymbol{\Delta})$ as functions of the substrate temperature.

Above $0.12 \mathrm{~Pa}$, the degradation of the crystallinity results from the increase of strain and low surface mobility of atoms at the surface of the films (Fig. 10).

\subsubsection{Morphological properties}

As for the influence of the substrate temperature, experiments as a function of the working pressure are in 


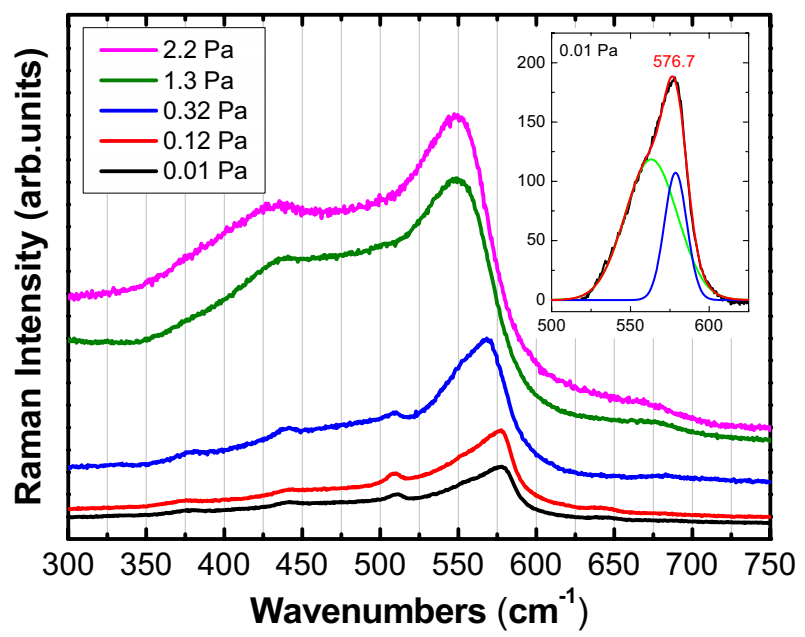

Fig. 8. (Color online) Raman spectra of $\mathrm{ZnO}$ :Al films deposited at various working pressures. The asymmetric $A_{1^{-}}$ $\mathrm{LO}$ vibration is fitted to two Gaussian contributions (example given in the inset).

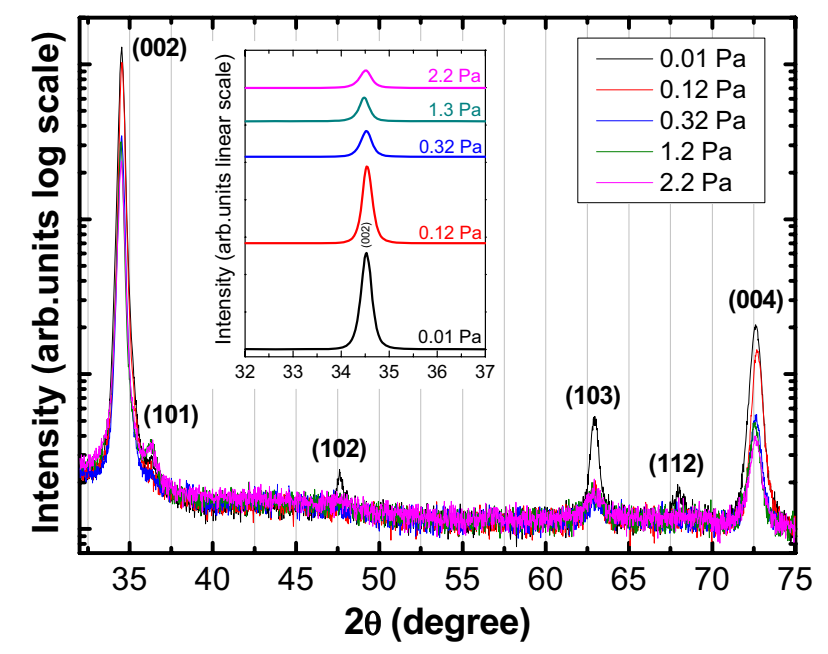

Fig. 9. (Color online) XRD profiles of $\mathrm{ZnO}: \mathrm{Al}$ films for various working pressures.

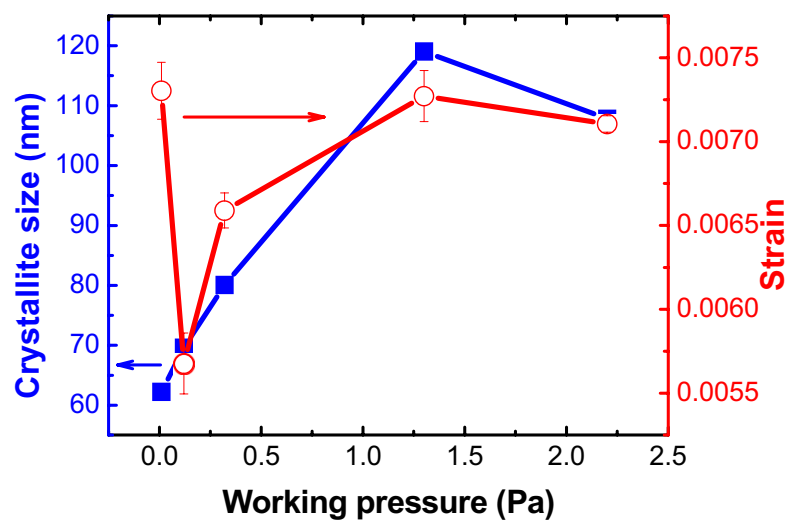

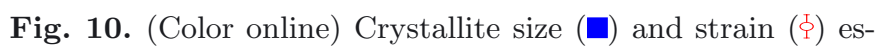
timated from Williamson-Hall plots for samples deposited at various working pressures.

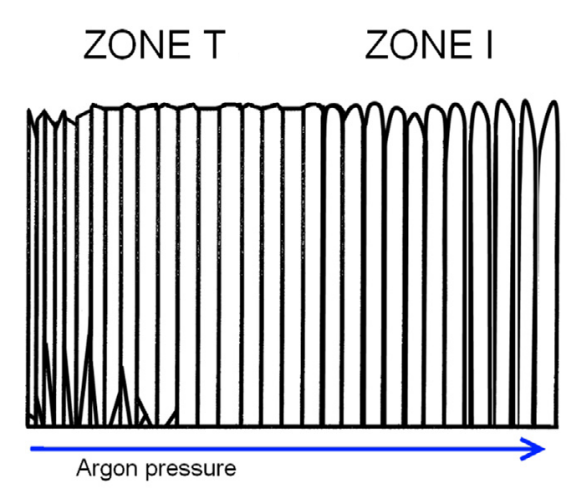

Fig. 11. (Color online) Structure zone model depending of the argon pressure. When increasing the working pressure from $0.01 \mathrm{~Pa}$ to $2.2 \mathrm{~Pa}$, at room temperature, the structure of the film transits from zone $\mathrm{T}$ to zone $\mathrm{I}$.

good agreement with the Thornton's structure zone model (Fig. 11). At low working pressure, the surface structure corresponds to the zone consisting of densely packed fibrous grains and relatively smooth domed surfaces. At low pressure as well as at high substrate temperature, the densely packed fibrous grains are revealed by the observation of (101), (102), (103) and (112) peaks (Fig. 9), when the growth competition is tougher because of the high mobility of the atoms at the surface of the growing film.

With the increase of the working pressure, the mean free path of the sputtered species decreases. The sputtered species undergo many collisions and as a result of their low energy these impinging particles have low surface mobility, causing the network compression (Fig. 10). The structure zone of films undergoes a transition from densely packed fibrous grains to a porous zone consisting of tapered crystallites separated by voids. (101), (102), (103) and (112) peaks are no longer observed (Fig. 9).

The microstructure predicted by the Thornton's structure zone model is confirmed by AFM images (Fig. 12). At low pressure, below $0.12 \mathrm{~Pa}$, the surface morphology is not distinguishable, while at high pressure, above $0.12 \mathrm{~Pa}$, crystallites are well defined, surrounded by voids. Low energy sputtered particles limit the mobility of surface atoms and self-shadowing effect becomes pronounced at high argon pressure, leading to an increase of the surface roughness. But below $0.12 \mathrm{~Pa}$, in densely packed fibrous grains zone, there is also an increase of the roughness, this time due to the bombardment by high energy ions. This bombardment introduces defects inside the films, leads to an increase in strain and a degradation of electrical properties. Surprisingly, the crystallinity of the films, as measured by Raman spectroscopy (Tab. 2) and X-Ray diffraction analysis (Fig. 9), seems not affected by the bombardment of sputtered particles.

\subsubsection{Electrical properties}

Above $0.12 \mathrm{~Pa}$, with the increase of the working pressure, a degradation of the electrical properties is observed, revealed by an increase in resistivity and a decrease in Hall 
C. Charpentier et al.: X-Ray diffraction and Raman spectroscopy in $\mathrm{ZnO}$ :Al growth process
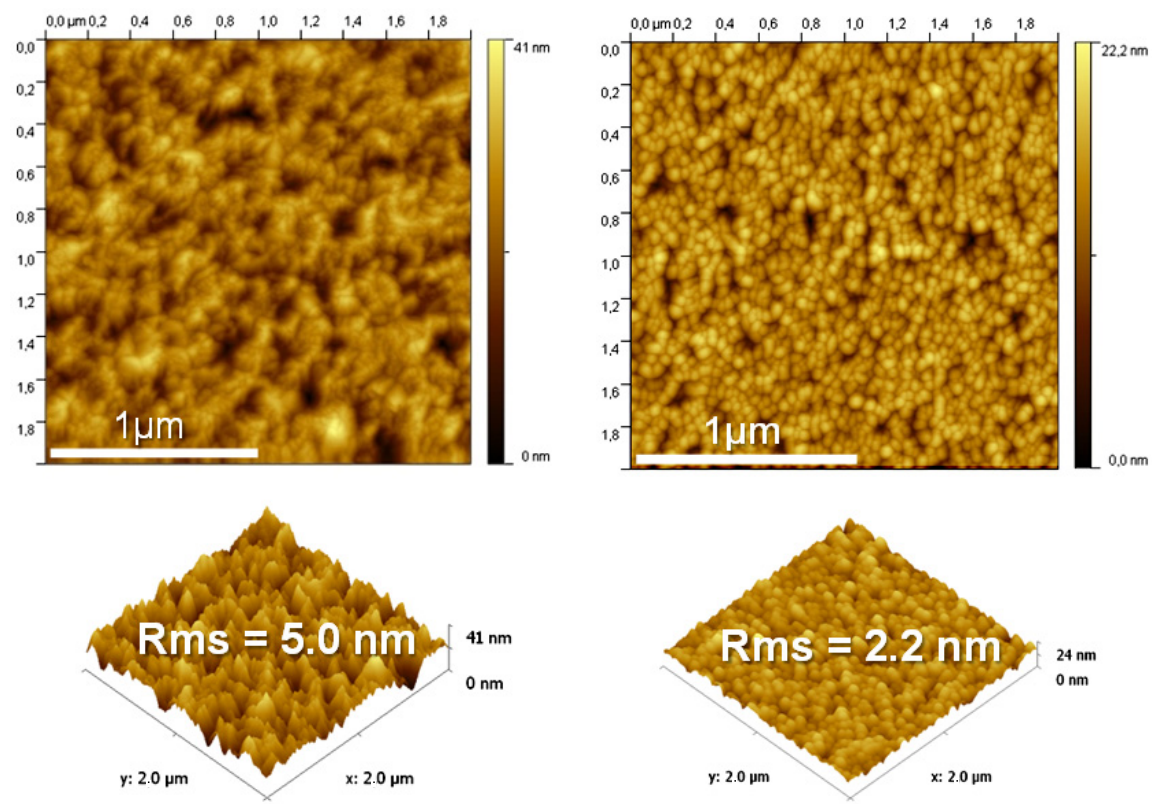

(a)

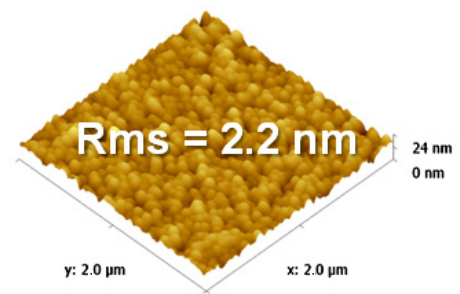

(b)
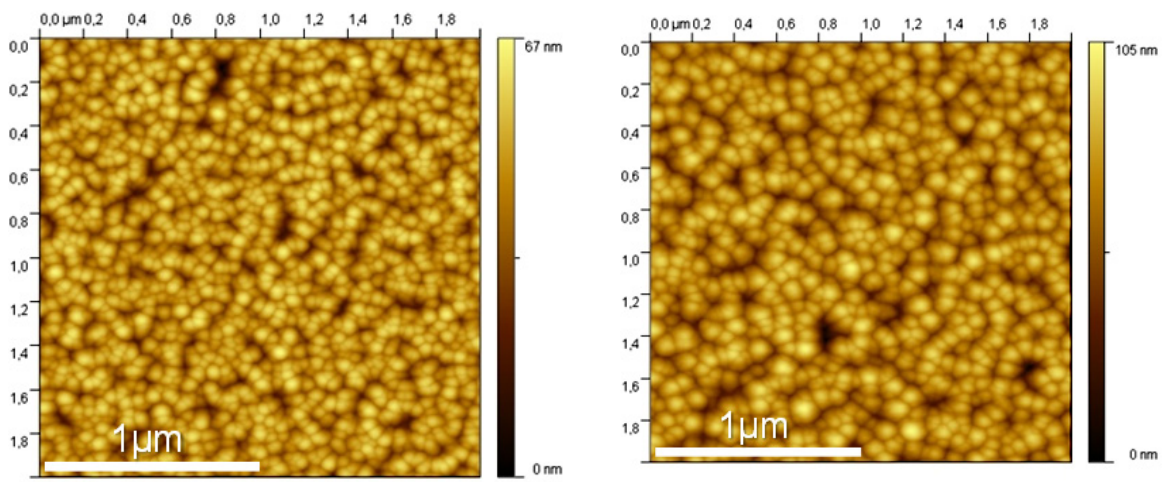

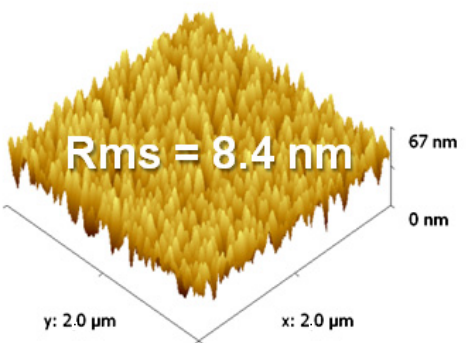

(c)

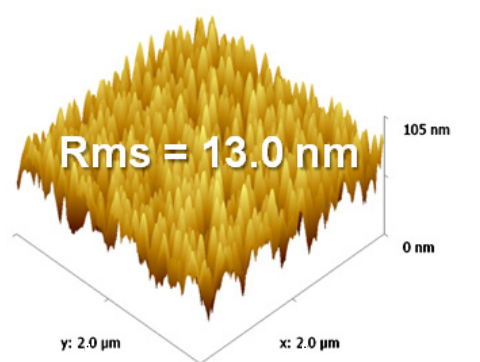

(d)

Fig. 12. (Color online) AFM images of the $\mathrm{ZnO}: \mathrm{Al}$ films as function of working pressure: (a) $0.01 \mathrm{~Pa}$, (b) $0.12 \mathrm{~Pa}$, (c) $0.32 \mathrm{~Pa}$, (d) $1.3 \mathrm{~Pa}$.

mobility (Fig. 13). At high pressure, the increase in surface roughness increases the effective surface area of the film and then enhances the number of adsorption sites for oxygen. The highly porous film structure intensifies the physisorption of oxygen after deposition at the grain boundaries which are scattering centres for carriers. Oxygen adsorbed on the surface of crystallites traps electrons, decreases the carrier concentration and also decreases the Hall mobility by increasing the potential barrier at the surface of crystallites.

\section{Conclusion}

By using X-Ray diffraction and Raman spectroscopy, a correlation between microstructural, morphological, electrical and optical properties is possible. Depending on substrate temperature and working pressure, two structure zones are observed: a densely packed fibrous grains zone at high temperature and low pressure, and a porous structure consisting of tapered crystallites separated by voids at high pressure. But the knowledge of the microstructure 


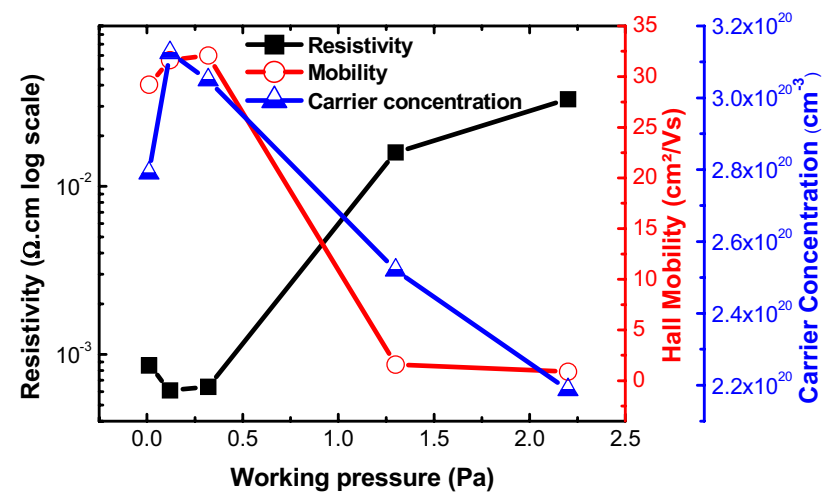

Fig. 13. (Color online) Resistivity (匹), Hall mobility $(\bigcirc)$ and carrier concentration $(\boldsymbol{\Delta})$ as functions of the working pressure.

is not sufficient to find the electrical optimum. Zones of densely packed fibrous grains exhibit an improvement of the crystallinity revealed by Raman spectroscopy and $\mathrm{X}$-Ray diffraction analysis, and a low strain. However, at low pressure, the high energy of sputtered particles enables a high mobility of atoms at the surface of the films but also leads to a high bombardment which creates defects, and degrades electrical properties of the films. Therefore the electrical optimum is in densely packed fibrous grains zone at high temperature, but at intermediate pressure.

\section{References}

1. B. Rech, T. Repmann, M.N. van den Donker, M. Berginski, T. Kilper, J. Hüpkes, S. Calnan, H. Stiebig, S. Wieder, Thin Solid Films 511, 548 (2006)

2. W. Beyer, J. Hüpkes, H. Stiebig, Thin Solid Films 516, 147 (2007)

3. J. Springer, B. Rech, W. Reetz, J. Muller, M. Vanecek, Solar Energy Mater. Solar Cells 85, 1 (2005)

4. J. Müller, B. Rech, J. Springer, M. Vanecek, Sol. Energy 77, 917 (2004)

5. J. Yoo, J. Lee, S. Kim, K. Yoon, I. Jun Park, S.K. Dhungel, B. Karunagaran, D. Mangalaraj, J. Yi, Thin Solid Films 480, $213(2005)$
6. O. Kluth, B. Rech, L. Houben, S. Wieder, G. Schöpe, Thin Solid Films 351, 247 (1999)

7. K. Ellmer, J. Phys. D 33, 17 (2000)

8. O. Kluth, G. Schöpe, J. Hüpkes, C. Agashe, J. Müller, B. Rech, Thin Solid Films 442, 80 (2003)

9. C. Agashe, O. Kluth, G. Schöpe, H. Siekmann, J. Hüpkes, B. Rech, Thin Solid Films 442, 167 (2003)

10. C. Agashe, O. Kluth, J. Hüpkes, U. Zastrow, B. Rech, J. Appl. Phys. 95, 1911 (2004)

11. Y. Igasaki, H. Kanma, Appl. Surf. Sci. 169, 508 (2001)

12. S. Rahmane, M.A. Djouadi, M.S. Aida, N. Barreau, B. Abdallah, N. Hadj Zoubir, Thin Solid Films 519, 5 (2010)

13. D. Song, A.G. Aberle, J. Xia, Appl. Surf. Sci. 195, 291 (2002)

14. S.-S. Lin, J.-L. Huang, Surf. Coat. Technol. 185, 222 (2004)

15. R. Wen, L. Wang, X. Wang, G.-H. Yue, Y. Chen, D.-L. Peng, J. Alloys Compd. 508, 370 (2010)

16. J. Woo, J. Lee, S. Kim, K. Yoon, I. Jun Park, S.K. Dhungel, B. Karunagaran, D. Mangalaraj, J. Yi, Phys. Stat. Sol. 2, 1228 (2005)

17. S. Singh, T. Ganguli, R. Kumar, R.S. Srinivasa, S.S. Major, Thin Solid Films 517, 661 (2008)

18. R. Chierchia, T. Böttler, H. Heinke, S. Einfeldt, S. Figge, D. Hommel, J. Appl. Phys. 93, 8918 (2003)

19. S. Singh, R.S. Srinivasa, S.S. Major, Thin Solid Films 515, $8718(2007)$

20. D. Song, Appl. Surf. Sci. 254, 4171 (2008)

21. M. Tzolov, N. Tzenov, D. Dimova-Malinovska, M. Kalitzova, C. Pizzuto, G. Vitali, G. Zollo, I. Ivanov, Thin Solid Films 379, 28 (2000)

22. Y.-C. Lee, S.-Y. Hu, W. Water, Y.-S. Huang, M.-D. Yang, J.-L. Shen, K.-K. Tiong, C.-C. Huang, Solid State Commun. 143, 250 (2007)

23. H. Morkoç, Ü. Özgür, in Zinc Oxide, Fundamentals, Materials and Device Technology (Wiley VCH, 2009)

24. J.B. Barna, M. Adamik, Thin Solid Films 317, 27 (1998)

25. F.C.M. Van De Pol, F.R. Blom, T.J.A. Popma, Thin Solid Films 204, 349 (1991)

26. J.A. Thornton, J. Vac. Sci. Technol. 11, 666 (1974)

27. J.A. Thornton, Annu. Rev. Mater. Sci. 7, 269 (1977) 